$10-1-2015$

\title{
Simple new risk score model for adult cardiac extracorporeal membrane oxygenation: simple cardiac ECMO score.
}

\author{
Graham Peigh \\ Thomas Jefferson University \\ Nicholas Cavarocchi \\ Thomas Jefferson University \\ Scott W. Keith \\ Thomas Jefferson University \\ Hitoshi Hirose \\ Thomas Jefferson University
}

Follow this and additional works at: https://jdc.jefferson.edu/surgeryfp

Part of the Cardiology Commons, and the Surgery Commons

Let us know how access to this document benefits you

\section{Recommended Citation}

Peigh, Graham; Cavarocchi, Nicholas; Keith, Scott W.; and Hirose, Hitoshi, "Simple new risk score model for adult cardiac extracorporeal membrane oxygenation: simple cardiac ECMO score." (2015). Department of Surgery Faculty Papers. Paper 139.

https://jdc.jefferson.edu/surgeryfp/139

This Article is brought to you for free and open access by the Jefferson Digital Commons. The Jefferson Digital Commons is a service of Thomas Jefferson University's Center for Teaching and Learning (CTL). The Commons is a showcase for Jefferson books and journals, peer-reviewed scholarly publications, unique historical collections from the University archives, and teaching tools. The Jefferson Digital Commons allows researchers and interested readers anywhere in the world to learn about and keep up to date with Jefferson scholarship. This article has been accepted for inclusion in Department of Surgery Faculty Papers by an authorized administrator of the Jefferson Digital Commons. For more information, please contact: JeffersonDigitalCommons@jefferson.edu. 


\section{Simple New Risk Score Model For Adult Cardiac ECMO.}

Graham Peigh $^{1}$, BA; Nicholas Cavarocchi ${ }^{1}$, MD; Scott W Keith ${ }^{2}$, PhD; Hitoshi Hirose ${ }^{1}$, MD, PhD.

From Departments of Surgery, ${ }^{1}$ Biostatistics, Pharmacology, and Experimental Therapeutics, ${ }^{2}$ Thomas Jefferson University, Philadelphia, PA.

Running head: Cardiac ECMO risk model.

Keywords: ECMO; Risk Factors; Cardiogenic shock; Survival.

Corresponding Author: Hitoshi Hirose, MD

Dept. Surgery, Thomas Jefferson University

1025 Walnut Street Room 605, Philadelphia, PA 19107, USA

Tel: 215-955-5654, Fax: 215-955-6010, Email: genex@nifty.com

This paper was presented at Academic Surgical Congress 2015, Las Vegas.

\section{Author's contributions:}

Graham Peigh: writing the article, data collection, analysis and interpretation Nicholas Cavarocchi: critical revision of the article.

Scott W Keith: analysis and interpretation, critical revision of the article.

Hitoshi Hirose: conception and design, data collection, analysis and interpretation, critical revision of the article.

Disclosure statement: All listed authors do not have any proprietary or commercial interest in any product mentioned or concept discussed in this article.

\section{Word Count of Main Text: 3464.}




\begin{abstract}
Introduction: While the use of cardiac ECMO is increasing in adult patients, the field lacks understanding of associated risk factors. Even though standard ICU risk scores such as SAPS II, SOFA and APACHE II, or disease specific scores such as MELD, RIFLE, PRESERVE and ECMOnet exist, they may not apply to adult cardiac ECMO patients as their risk factors differ from variables used in these scores.
\end{abstract}

Methods: Between 2010 and 2014, 73 ECMO were performed for cardiac support at our institution. Patient demographics and survival were retrospectively analyzed. A new easily calculated score for predicting ECMO mortality was created using identified risk factors from univariate and multivariate analyses, and model discrimination was compared to other scoring systems.

Results: Cardiac ECMO was performed on 73 patients (47 males and 26 females) with a mean age of $48 \pm 14$ years. $64 \%$ of patients (47/73) survived ECMO support. Pre-ECMO SAPS II, SOFA, APACHE II, MELD, RIFLE, ECMOnet, and PRESERVE scores were not correlated with survival. Univariate analysis of pre-ECMO risk factors demonstrated that elevated lactate, renal dysfunction, and post-cardiotomy cardiogenic shock were risk factors for death. Applying this data into a new Simplified Cardiac ECMO Score (minimal risk = 0, maximal $=5$ ) predicted patient survival. Survivors had a lower risk score $(1.8 \pm 1.2)$ vs. the non-survivors $(3.0 \pm 0.99)$, $\mathrm{p}<0.0001$.

Conclusions: Common ICU or disease specific risk scores calculated for cardiac ECMO patients did not correlate with ECMO survival, while a new Simplified Cardiac ECMO Score provides survival predictability.

Word count of abstract: $249 / \max 250$ 


\section{Introduction}

For patients with reversible cardiac or respiratory injuries who would otherwise face grim outlooks and high mortality rate, extracorporeal membrane oxygenation (ECMO) continues to provide hope for successful recovery. The literature reports that hospital survival rates after being supported by ECMO range widely from $20 \%$ to $65 \%{ }^{1,2,3,4}$ Since the indications for ECMO used to support a patient with cardiac or respiratory failure can differ greatly, it is important to consider these two populations as different when doing specific analyses.

Patients on ECMO for cardiac failure are supported by veno-arterial (VA) ECMO. ECMO provides reasonable recovery for patients suffering from cardiac failure as ECMO survival rates range from $50 \%$ to $69 \%{ }^{5,6,7,8}$ and hospital discharge rates range from $25 \%$ to $45 \%$. 7,5, 9, 10 With the use of ECMO for patient salvage from refractory cardiogenic shock in adult populations increasing exponentially, a comprehensive analysis of risk factors associated with the treatment, with the aim of creating a simple risk model, has yet to be completed.

While the literature sets forth an impressive breadth of potential risk factors associated with cardiac ECMO mortality, there is no clear risk score that can predict the probability of survival for a patient requiring cardiac ECMO. ${ }^{5-7,11,12}$ Even though several intensive care unit (ICU) risk models exist that predict mortality among all ICU patients, patients being supported on cardiac ECMO may have different risk and treatment profiles compared to other ICU populations. These common risk scores such as Simplified Acute Physiology Score II (SAPS II), ${ }^{13}$ Sequential Organ Failure Assessment (SOFA), ${ }^{14}$ and Acute Physiology And Chronic Health Evaluation II (APACHE II) ${ }^{15}$ may not apply for cardiac ECMO patients.

The present study assesses the survival rate of cardiac ECMO patients at our institution and attempts to distil a concise and generalizable set of risk factors that apply to this sub-group of cardiogenic shock patients. Also, this study seeks to determine if the common ICU or disease specific risk models (SAPS II, SOFA, and APACHE II) apply to cardiac ECMO patients. While a number of these risk models have been tested in mixed ECMO patient populations previously, 
$16,17,18$ many have yet to be assessed in a patient population specific to cardiac ECMO. Finally, using the risk factors generated, this study attempts to create and verify a new Simple Cardiac ECMO Score, which can be used preoperatively to predict ECMO mortality for cardiac ECMO patients.

\section{Methods}

Between August 2010, and June 2014, 107 adult ECMO procedures were performed at our institution. Among those, 73 ECMO procedures were primarily done for cardiac support. The standard procedure for cardiac ECMO patients was VA ECMO. The VA ECMO procedure involved placing a peripheral ECMO cannula though the femoral artery and vein, along with distal limb perfusion cannula, ${ }^{19}$ unless the patient had open chest and peripheral access was not feasible at the time of VA ECMO placement. No patient was placed on VV ECMO for cardiac support in our institution. Patient data was entered in a structured IRB approved database. The latest laboratory value prior to ECMO insertion was entered into the database. The data was retrospectively analyzed for information regarding patient demographics, preoperative (preECMO) and perioperative (peri-ECMO) conditions, survival, and organ recovery data. The endpoint of this study was ECMO survival vs. ECMO mortality. ICU scores such as SOFA, APACHE II, and SAPS II, and an organ specific score (Model for End-stage Liver Disease [MELD], and Kidney Risk, Injury, Failure, Loss of function, ESRD [RIFLE]) were calculated. Other scores specifically related to ECMO including the ECMOnet ${ }^{20}$ and Predicting Death for Severe ARDS on VV ECMO (PRESERVE) ${ }^{21}$ scores were calculated as well.

The results were expressed as number with percentage, or mean \pm standard deviation. Univariate analyses were performed using chi-square or Fisher's exact tests for categorical variables, and Student's t-tests for continuous variables as appropriate to identify the risk factors of death during ECMO. Multivariate analyses were performed on the variables found to have a $\mathrm{p}$ $<0.1$ according to univariate analyses to identify independent risk factors for ECMO mortality. A new model to predict ECMO mortality (Simplified Cardiac ECMO Score) was created using the 
dominant risk factors, as isolated by univariate and multivariate analyses, and reflecting the logistic regression relationships between selected predictor indicator variables and ECMO mortality outcome indicators. Receiver operating characteristic curve (ROC) and area under the curve (AUC) analyses were performed using SAS Software (version 9.4, SAS Institute, Cary, NC). The model discrimination was examined by comparing the AUC of the Simplified Cardiac ECMO Score to the AUCs of other conventional ICU and organ specific scores. P-values $<0.05$ were considered to be significant.

\section{Results}

The 73 patients who received cardiac ECMO at our institution consisted of 47 males and 26 females with a mean age of $48 \pm 14$ years. The etiologies for ECMO in these patients were acute myocardial infraction (AMI) $(n=19)$, acute on chronic heart failure $(n=14)$, post-cardiotomy failure ( $n=13)$, malignant arrhythmia $(n=11)$, myocarditis $(n=5)$, Takotsubo cardiomyopathy $(n=2)$, accidental hypothermia $(n=2)$, acute rejection $(n=2)$, pulmonary embolism $(n=2)$, constrictive pericarditis $(n=1)$, drug overdose cardiac arrest $(n=1)$, and septic shock $(n=1)$. The average duration of ECMO support in these patients was $9.2 \pm 6.1$ days. Among the 73 patients, 47 patients (64\%) survived ECMO. Causes of death in patients who died on ECMO included anoxic brain injury $(n=8)$, stroke $(n=8)$, irreversible cardiac dysfunction $(n=3)$, sepsis $(n=3)$, irreversible lung disease $(\mathrm{n}=2)$, abdominal compartment syndrome with hepato-renal syndrome $(n=1)$, and failure to control bleeding $(n=1)$. There were no ECMO device related deaths. Among the 47 ECMO survivors, 39 had improved or unchanged kidney function (83\%), 44 had improved or unchanged liver function (94\%), 46 had improved or unchanged lactate trend (98\%), and 43 had improved or unchanged pulmonary edema represented by Murray score (91\%) (Table $1)$.

Among the ECMO survivors, 27/47 patients (57\%) were discharged from the hospital. Causes of death post-ECMO but prior to discharge included sepsis $(n=5)$, neurologic injury $(n=4)$, AMI due to stent thrombosis ( $n=2)$, family's withdrawal due to failure to thrive $(n=2)$, and one 
case of each of the following: pulseless electric activity after internal defibrillator placement, persistent loss of cardiac activity despite biventricular assist device placement, acute failure of left ventricular assist device placement with persistent low flow and malperfusion, non-resectable cardiac metastasis (adenocarcinoma), and severe coagulopathy and multiple bleeding. Note that 3 patients required two separate cardiac ECMO runs within the same hospital stay. One of these patients died on the second ECMO run, while two died post ECMO removal.

After univariate analysis of potential pre-ECMO risk factors, high lactate levels $(\mathrm{p}=0.02)$, the presence of post-cardiotomy failure $(\mathrm{p}=0.03)$, and a RIFLE score injury or above $(\mathrm{p}=0.10)$ were associated with ECMO mortality (Table 2). We performed separate analyses to attempt to identify the risk factors for hospital mortality. Only pre-ECMO bicarbonate levels correlated with hospital mortality (Survivors: $18.3 \pm 5.2$; Non-survivors: $22.2 \pm 6.4 ; \mathrm{p}=0.03$ ).

A new Simplified Cardiac ECMO Score for ECMO mortality was built and applied to this sample. A potential pre-ECMO risk factor p-value less than or equal to 0.1 as determined by univariate analyses was considered to be a factor for inclusion into new ECMO score. It was found that the combination of elevated lactate $(>2.0 \mathrm{mmol} / \mathrm{dl})$, renal dysfunction (RIFLE score of ‘injury’ or above), and post-cardiotomy predicted death. According to multivariate logistic regression analysis, presence of high lactate and post-cardiotomy each had approximately a twofold greater contribution to the odds of dying on ECMO than the presence of renal dysfunction (Table 3). When combining these parameters into a simply calculated score as shown in Table 3, the Simplified Cardiac ECMO Scores (minimum = 0, maximum = 5) were significantly different between ECMO survivors and non-survivors $(p<0.001)$, while no such differences were detected for among any of the other pre-ECMO ICU or disease-specific risk scores (Table 4). The mortality rates progressively increased with a higher Simplified Cardiac ECMO Score; mortality was $0 \%$ (deaths/number of patients $=0 / 10$ ) for a Simple Cardiac ECMO Score of 0, 20\% (1/5) for a Score of $1,29 \%(6 / 21)$ for a Score of 2, 50\% (11/22) for a Score of 3, 71\% (5/7) for a Score of 4, and 100\% (2/2) for a score of 5 (Figure 1). The Simplified Cardiac ECMO Score and these 
mortality percentages had a linear correlation $([$ mortality\% $]=19.26 \times[$ Simple Cardiac ECMO Score $\left.]-22.4, \mathrm{R}^{2}=0.98\right)$.

Following the production of ROC curves an analysis of the AUCs for the previously mentioned ICU and disease-specific risk scores was completed, along with the Simplified Cardiac ECMO Score (Figure 2-4). The Simple Cardiac ECMO Score demonstrated significantly better prediction of ECMO mortality $(\mathrm{AUC}=0.77)$ as compared to SAPS II, SOFA, MELD, RIFLE, and PRESERVE scores (AUC $\leq 0.60$, Table 5). Statistical significance was not reached relative to APACHE II and ECMOnet scores.

\section{Discussion}

The ECMO and hospital survival results from our institution are consistent with those from other previous studies of cardiac ECMO. ${ }^{5,6,7,9,10}$ However, there remains limited data from previous studies to suggest which patients make good candidates for cardiac ECMO, and which patients are futile cases. While previous studies have determined various risk factors for cardiac ECMO patients, no studies to date have isolated a specific risk score for this patient population. By utilizing an easily calculated risk score for cardiac ECMO patients, physicians can evaluate in which patients the use of cardiac ECMO presents elevated risk of mortality.

While the majority of cardiac ECMO patients are supported in the ICU, traditional ICU risk scores do not apply because they utilize variables that do not apply to most ECMO patients. For example, in the APACHE II, SOFA and SAPS II scores, $\mathrm{PaO}_{2}$ and $\mathrm{FiO}_{2}$ measures are irrelevant because most cardiac ECMO patients are intubated and in pulmonary edema. The inclusion of the Glasgow Coma Scale (GCS) is not warranted because most patients with cardiogenic shock are sedated. ${ }^{13-15}$ In addition, the SAPS II score takes type of admission, and whether the patient has any chronic diseases into account, both of which are not pertinent data points for survival considerations of cardiac ECMO patients. ${ }^{13}$ In a study that assessed patients started on ECMO for refractory post-cardiotomy shock, it was found that a EuroSCORE of greater than $20 \%$ was associated with mortality. ${ }^{7}$ The EuroSCORE was designed to predict the 
mortality of patients who undergo cardiac surgery and it may co-relate to the outcomes of postcardiotomy failure patients; however, it has minimum value to patients without cardiac surgery.

ECMOnet and PRESERVE scores have both been shown to predict mortality in respiratory ECMO patients. ${ }^{20,21}$ While these patients are on ECMO support, the etiologies for ECMO in these patients differ greatly from those being supported on cardiac ECMO. As such, the predictors of death in these patients will vary from those of cardiac ECMO patients. ECMOnet scores include measures on pre-ECMO length of stay and hypotension, neither of which are relevant for cardiac ECMO mortality assessments. ${ }^{20}$ Cardiac ECMO patients are often given vasopressors, so their blood pressure readings can be artificially manipulated. Finally, the PRESERVE score uses many respiratory measures such as PEEP, plateau pressure, and status on mechanical ventilation — none of which are pertinent for cardiac ECMO patients. ${ }^{21}$ Though respiratory function may be of utmost relevance to respiratory ECMO mortality, it bears little influence on cardiac ECMO mortality because of the differing etiologies for and courses of treatment. While a number of studies have assessed the ability of previously-verified risk scores to predict mortality in all ECMO patients (both cardiac and respiratory), because the etiologies for ECMO in these two patient groups differ so widely, it is our impression that these two populations must be considered separately. ${ }^{1,17,18}$

An organ system-specific score, the MELD score, also showed a poor correlation with cardiac ECMO mortality. This is likely because the MELD score was designed specifically to predict mortality in patients with primary liver failure, but the liver dysfunction in cardiac ECMO patients are more likely secondary to cardiogenic shock. ${ }^{22}$ The MELD score was primarily designed to evaluate patients for potential liver transplants, and a prerequisite for its usage is normal cardiac function. ${ }^{22}$ Cardiac ECMO patients have severely compromised cardiac function, and the MELD score cannot be applied to this patient population.

One of the factors incorporated into the Simple Cardiac ECMO Score was a patient's RIFLE score, as RIFLE values greater than or equal to 'injury' were nearly significant (survivors: 
16 [34\%], Non-survivors 14 [54\%], $\mathrm{p}=0.100)$. This is likely due to the fact that kidney function is an important factor in ECMO survival, since other essential states such as metabolic acidosis and high lactate could be related to renal function. However, when comparing the AUC of the RIFLE score to that of the Simple Cardiac ECMO Score, the latter showed a statistically significant stronger association with positive prediction. This is because RIFLE does not portray the entire clinical picture of patients with cardiogenic shock.$^{23}$ Metabolic acidosis and high lactate in cardiogenic shock patients reflect the degree of poor perfusion due to cardiac failure, more so than direct kidney injury. Kidney failure can be supported with temporary continuous veno-veno hemodialysis.

The issue of pre-ECMO lactate levels correlating with ECMO survival is widely discussed in the literature. A number of sources claim that lactate levels do influence survival, ${ }^{7}$, ${ }^{10}$ while others have failed to find a connection. ${ }^{6}$ Our patient sample demonstrated that elevated lactate levels independently predicted mortality in the population. This lactate level may reflect the degree of malperfusion prior to ECMO. We were unable to identify a series discrete lactate levels that progressively increased the utility of our model. Rather than investigating various cutoff points for lactate levels, we used a marker of 'normal' or 'abnormal' levels to keep our score easy and simple to calculate. Post-cardiotomy cardiogenic shock in our patient sample yielded significant mortality results, suggesting it greatly impacts cardiac ECMO survival as well. After performing multivariate analysis, both high lactate and post-cardiotomy had approximately double the predictive odds of renal dysfunction. Accordingly, we have given elevated lactate and the diagnosis of being post-cardiotomy double the weight of renal dysfunction in our scoring system.

The implementation of the Simplified Cardiac ECMO Score yielded an acceptable AUC value, suggesting beneficial clinical utility. In addition to the above listed shortcomings for the cardiac ECMO patient population, all the ICU, disease-specific, and other ECMO-specific scores are very difficult to calculate, and often require software to determine expected mortality. This 
can take valuable time when in an emergent situation, and can also potentially dissuade clinicians from using the scores at all. Importantly, the Simplified Cardiac ECMO is easy to calculate. Unlike many other risk scores, physicians do not need an algorithm or calculator to calculate the Simple Cardiac ECMO Score. Clinicians who are treating the refractory cardiogenic patient can simply calculate this Simple Cardiac ECMO Score in their head to have a well-informed view of the patient's prognosis. The intention of this score is not to exclude patients from cardiac ECMO. However, in a setting in which demand for ECMO exceeds the resources of a particular hospital, this score may help physicians allocate hospital resources appropriately. This scoring system may also help physicians determine the prognosis of patients on cardiac ECMO to assess potential recovery.

Because our sample size was limited, we were unable to show a statistically significant increase in AUC relative to two of the other risk scores analyzed. Moreover, we did not have a sufficient sample to rigorously validate the model. That said, the Simplified Cardiac ECMO Score did provide a significantly higher predictive capacity, as measured by AUC, relative to five other risk scores, and it provides an early guide to identify futile cases in this high-risk patient population. This study assesses risk factors for the cardiac ECMO procedure itself, rather than hospital discharge. This is because being successfully discharged from the hospital can be altered by many post-ECMO issues, and may not be directly related to the ECMO procedure. In fact, separate analyses showed that only pre-ECMO bicarbonate levels predicted hospital mortality and we failed to create risk model. This study was also limited by its retrospective nature from a single institution. Future research should use the Simplified Cardiac ECMO Score in larger samples of cardiac ECMO patients to determine its utility in accurately predicting ECMO mortality in the population when compared with other ICU risk scores.

\section{Conclusion}

Commonly used ICU and disease-specific risk scores do not accurately predict ECMO mortality for patients supported on ECMO for primary cardiac failure. The Simple Cardiac 
ECMO Score, determined by post-cardiotomy, renal failure, and high lactate, successfully predicted ECMO mortality. This score may help physicians avoid futile efforts and allocate resources in an effective and efficient manner. 
Table 1: Organ function before and after ECMO (ECMO Survivors)

\begin{tabular}{|l|c|c|}
\hline & Pre-ECMO & $\begin{array}{c}\text { Before ECMO } \\
\text { decannulation }\end{array}$ \\
\hline Creatinine $(\mathrm{mg} / \mathrm{dl})$ & $1.5 \pm 0.8$ & $1.2 \pm 0.5$ \\
\hline Alanine aminotransferase (IU/L) & $260 \pm 629$ & $79 \pm 142$ \\
\hline Lactate $(\mathrm{mmol} / \mathrm{L})$ & $5.5 \pm 4.5$ & $1.6 \pm 1.0$ \\
\hline Murray score & $2 \pm 1.5$ & $1 \pm 0.9$ \\
\hline
\end{tabular}


Table 2: Univariate analyses of patient demographics, clinical risk factors, laboratory data before ECMO.

\begin{tabular}{|c|c|c|c|}
\hline & $\begin{array}{c}\text { ECMO } \\
\text { Survivors } \\
\mathrm{N}=47\end{array}$ & $\begin{array}{c}\text { ECMO } \\
\text { Non-Survivors } \\
\mathrm{N}=26\end{array}$ & $\mathrm{p}$ \\
\hline \multicolumn{4}{|l|}{ Pre ECMO demographics } \\
\hline Age & $49 \pm 13$ & $48 \pm 15$ & 0.780 \\
\hline Male gender & $33(70 \%)$ & $14(54 \%)$ & 0.162 \\
\hline Body weight (kg) & $90 \pm 27$ & $81 \pm 21$ & 0.135 \\
\hline Body mass index $\left(\mathrm{kg} / \mathrm{m}^{2}\right)$ & $29 \pm 7.0$ & $29 \pm 7.1$ & 0.726 \\
\hline \multicolumn{4}{|l|}{ Clinical risk factors } \\
\hline Smoking history & $16(34 \%)$ & $5(19 \%)$ & 0.181 \\
\hline Coronary artery disease & $20(43 \%)$ & $12(46 \%)$ & 0.767 \\
\hline Diabetes & $12(26 \%)$ & $9(35 \%)$ & 0.412 \\
\hline \multicolumn{4}{|l|}{ Primary Diagnosis } \\
\hline Acute myocardial infraction & $14(30 \%)$ & $5(19 \%)$ & 0.325 \\
\hline Post-cardiotomy failure & $5(11 \%)$ & $8(31 \%)$ & 0.031 \\
\hline E-CPR & $14(30 \%)$ & $7(27 \%)$ & 0.800 \\
\hline \multicolumn{4}{|l|}{ Laboratory data } \\
\hline White blood cell count (B/L) & $13.5 \pm 6.5$ & $13.9 \pm 5.8$ & 0.772 \\
\hline Hemoglobin (g/dl) & $11.6 \pm 3.1$ & $11.3 \pm 2.7$ & 0.629 \\
\hline Platelet count $(\mathrm{B} / \mathrm{L})$ & $211 \pm 143$ & $179 \pm 107$ & 0.283 \\
\hline $\mathrm{PaO}_{2}(\mathrm{~mm} \mathrm{Hg})$ & $149 \pm 116$ & $126 \pm 114$ & 0.434 \\
\hline $\mathrm{PaCO}_{2}(\mathrm{~mm} \mathrm{Hg})$ & $41 \pm 12$ & $44 \pm 19$ & 0.454 \\
\hline $\mathrm{HCO}_{3}(\mathrm{mmol} / \mathrm{L})$ & $20 \pm 6.0$ & $18 \pm 6.0$ & 0.252 \\
\hline $\mathrm{HCO}_{3}<20 \mathrm{mmol} / \mathrm{L}$ & $20(43 \%)$ & $13(50 \%)$ & 0.540 \\
\hline Creatinine $(\mathrm{g} / \mathrm{dl})$ & $1.5 \pm 0.8$ & $1.7 \pm 0.8$ & 0.254 \\
\hline RIFLE score injury or above & $16(34 \%)$ & $14(54 \%)$ & 0.100 \\
\hline Bilirubin (mg/dl) & $1.4 \pm 1.4$ & $2.0 \pm 2.3$ & 0.256 \\
\hline Aspartate transaminase (IU/L) & $520 \pm 1936$ & $612 \pm 1195$ & 0.812 \\
\hline Lactate $(\mathrm{mmol} / \mathrm{L})$ & $5.5 \pm 4.9$ & $9.4 \pm 7.4$ & 0.020 \\
\hline Lactate $>2 \mathrm{mmol} / \mathrm{L}$ & $31(66 \%)$ & $24(92 \%)$ & 0.012 \\
\hline
\end{tabular}

E-CPR: ECMO assisted cardiopulmonary resuscitation. 
Table 3: Multivariate logistic regression analyses of ECMO mortality.

\begin{tabular}{|l|c|c|c|c|}
\hline & $\begin{array}{c}\text { Odds } \\
\text { Ratio }\end{array}$ & Chi square & $\mathrm{p}$ & $\begin{array}{c}\text { Proposed } \\
\text { weight for New } \\
\text { Simplified } \\
\text { ECMO Score }\end{array}$ \\
\hline Post-cardiotomy & 1.99 & 6.33 & 0.012 & $\mathbf{2}$ \\
\hline Lactate above 2 & 2.39 & 6.29 & 0.012 & $\mathbf{2}$ \\
\hline RIFLE score injury or above & 1.22 & 3.82 & 0.050 & $\mathbf{1}$ \\
\hline
\end{tabular}


Table 4: Analyses of ICU, disease specific, and ECMO related scores.

\begin{tabular}{|l|c|c|c|}
\hline Pre-ECMO Scores & $\begin{array}{c}\text { ECMO } \\
\text { Survivors }\end{array}$ & $\begin{array}{c}\text { ECMO } \\
\text { Non-Survivors }\end{array}$ & \multicolumn{1}{c|}{} \\
\hline SAPS II & $51.7 \pm 17.7$ & $54.6 \pm 18.3$ & 0.626 \\
\hline SOFA & $13.2 \pm 2.5$ & $13.6 \pm 2.5$ & 0.485 \\
\hline APACHE II & $28.8 \pm 8.02$ & $31.9 \pm 7.4$ & 0.136 \\
\hline MELD & $16.3 \pm 7.9$ & $19.6 \pm 9.6$ & 0.155 \\
\hline PRESERVE & $5.5 \pm 2.7$ & $5.4 \pm 2.5$ & 0.959 \\
\hline ECMOnet & $4.7 \pm 1.8$ & $5.6 \pm 2.1$ & 0.076 \\
\hline Simple Cardiac ECMO Score & $1.8 \pm 1.2$ & $3.0 \pm 0.99$ & $<0.001$ \\
\hline
\end{tabular}

APACHE II: acute physiology and chronic health evaluation II; ECMO: extracorporeal membrane oxygenation; MELD: model for end-stage liver disease; PRESERVE: predicting death for severe ARDS on VV ECMO; RIFLE: kidney risk, injury, failure, loss of function, ESRD;

SAPS II: simplified acute physiology score II ; SOFA: sequential organ failure assessment score. 
Table 5: Comparisons of area under the curves (AUCs)

\begin{tabular}{|l|c|c|}
\hline Score & AUC & $\begin{array}{c}\mathrm{p} \\
\text { (Compared to Simple Cardiac ECMO Score) }\end{array}$ \\
\hline Simple Cardiac ECMO & 0.77 & ---- \\
\hline SAPS II & 0.54 & 0.0026 \\
\hline SOFA & 0.55 & 0.0019 \\
\hline APACHE II & 0.60 & 0.2043 \\
\hline MELD & 0.57 & 0.0183 \\
\hline RIFLE & 0.60 & 0.0315 \\
\hline PRESERVE & 0.49 & 0.0050 \\
\hline ECMO net & 0.62 & 0.1002 \\
\hline
\end{tabular}

APACHE II: acute physiology and chronic health evaluation II; MELD: model for end-stage liver disease; PRESERVE: predicting death for severe ARDS on VV ECMO; RIFLE: kidney risk, injury, failure, loss of function, ESRD; SAPS II: simplified acute physiology score II; SOFA: sequential organ failure assessment score. 
Figure 1: Survival Percentages for each Simplified Cardiac ECMO Score. Presence of each of the following pre-ECMO predictors count as points toward the aggregated score: Lactate $>2$ $\mathrm{mmol} / \mathrm{dl}$ (2 points), Renal injury or above including injury, failure, and loss) (1 point), PostCardiotomy (2 points).

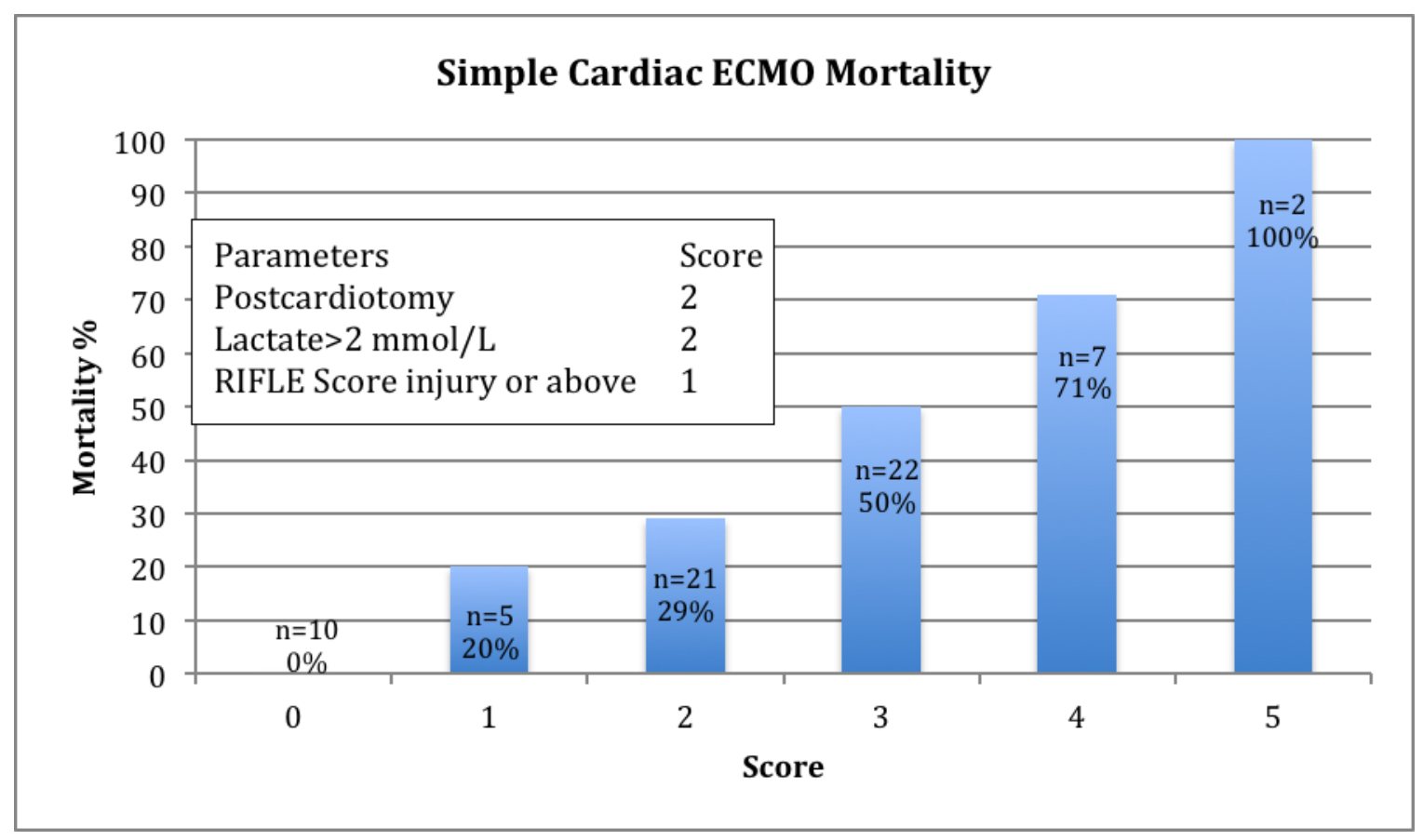


Figure 2: Receiver operating characteristic curves for Simple Cardiac ECMO, APACHE II, SOFA, and SAPS II. APACHE II: acute physiology and chronic health evaluation II; ECMO: extracorporeal membrane oxygenation; SAPS II: simplified acute physiology score II ; SOFA: sequential organ failure assessment score.

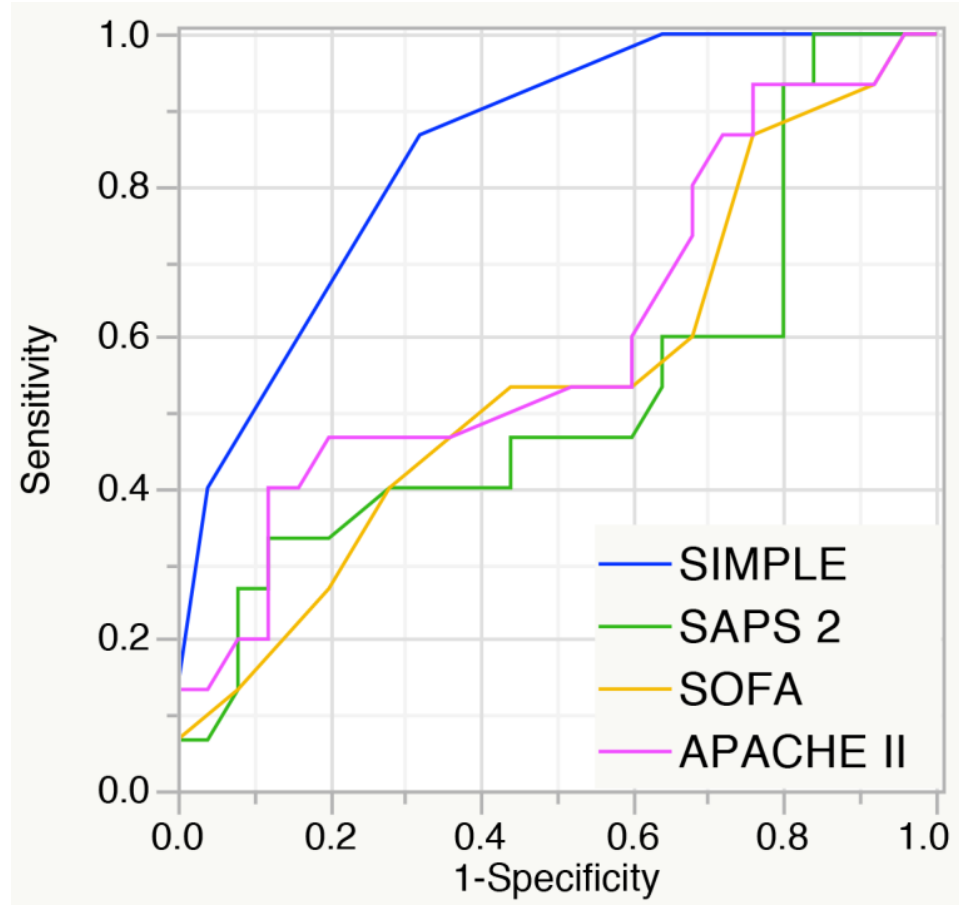


Figure 3: Receiver operating characteristic curves for Simple Cardiac ECMO, PRESERVE, and ECMOnet. ECMO: extracorporeal membrane oxygenation; PRESERVE: predicting death for severe ARDS on VV ECMO.

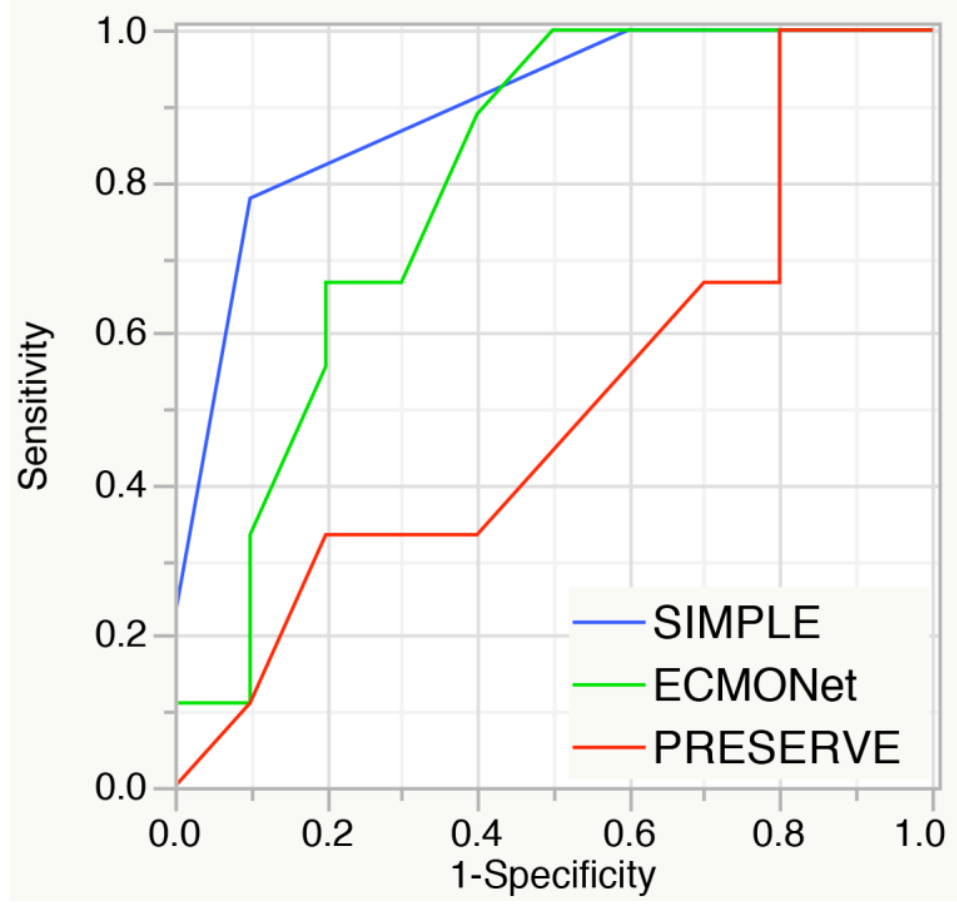


Figure 4: Receiver operating characteristic curves for Simple Cardiac ECMO, MELD and RIFLE score. ECMO: extracorporeal membrane oxygenation; MELD: model for end-stage liver disease; RIFLE: kidney risk, injury, failure, loss of function, ESRD.

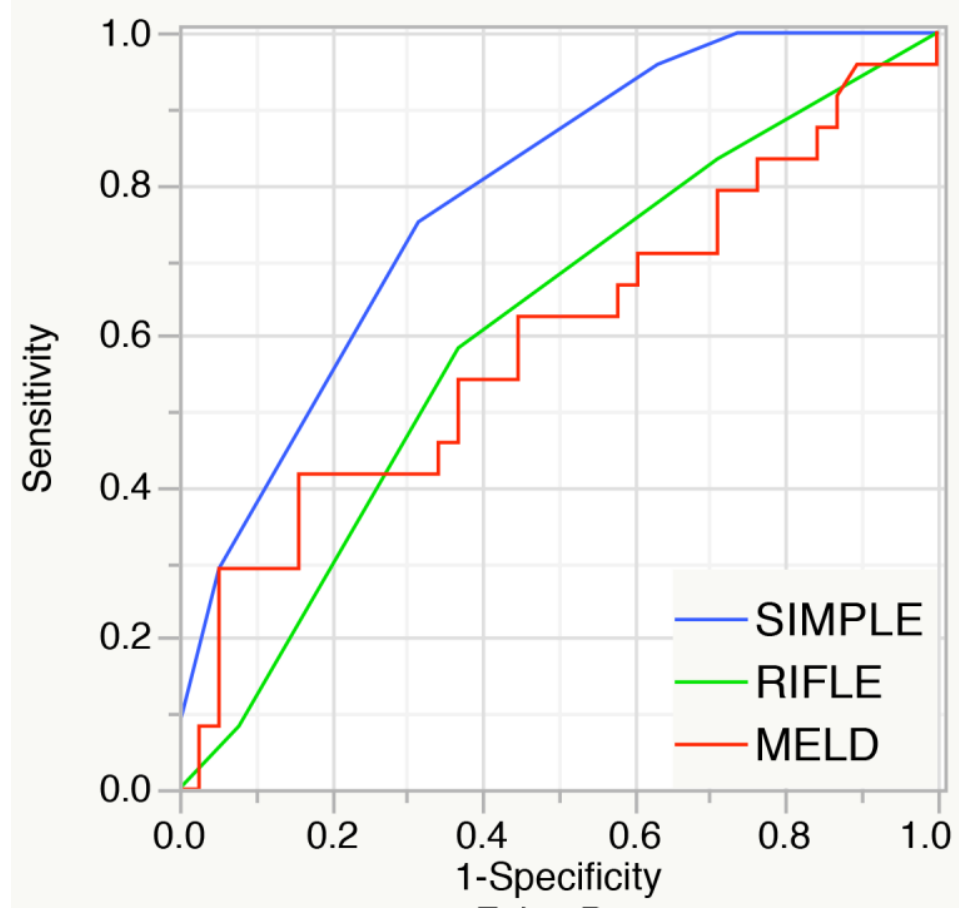




\section{References}

${ }^{1}$ Chen YC, Tsai FC, Chang CH, Lin CY, Jenq CC, Juan KC, et al. Prognosis of patients on extracorporeal membrane oxygenation: the impact of acute kidney injury on mortality. Ann Thorac Surg 2011;91:137-42.

${ }^{2}$ Zangrillo A, Landoni G, Biondi-Zoccai G, Greco M, Greco T, Frati G, et al. A meta-analysis of complications and mortality of extracorporeal membrane oxygenation. Crit Care Resusc $2013 ; 15: 172$.

${ }^{3}$ Cheng R, Hachamovitch R, Kittleson M, Patel J, Arabia F, Moriguchi J, et al. Complications of extracorporeal membrane oxygenation for treatment of cardiogenic shock and cardiac arrest: a meta-analysis of 1,866 adult patients. Ann Thorac Surg 2014;97:610-16.

${ }^{4}$ Hei F, Lou S, Li J, Yu K, Liu J, Feng Z, et al. Five year results of 121 consecutive patients treated with extracorporeal membrane oxygenation at Fu Wai hospital. Artif organs 2011;35:572-78.

${ }^{5}$ Beiras-Fernandez A, Deutsch MA, Kainzinger S, Kaczmarek I, Sodian R, Ueberfuhr P, et al. Extracorporeal membrane oxygenation in 108 patients with low cardiac output-a single-center experience. Intl J Artif Organs 2011;34:365-73.

${ }^{6}$ Hsu PS, Chen JL, Hong GJ, Tsai YT, Lin CY, Lee CY, et al. Extracorporeal membrane oxygenation for refractory cardiogenic shock after cardiac surgery: predictors of early mortality and outcome from 51 adult patients. Euro J Cardiothorac Surg 2010;37:328-33.

${ }^{7}$ Rastan AJ, Dege A, Mohr M, Doll N, Falk V, Walther T, et al. Early and late outcomes of 517 consecutive adult patients treated with extracorporeal membrane oxygenation for refractory postcardiotomy cardiogenic shock. J Thorac Cardiovasc Surg 2010;139:302-11.

${ }^{8}$ Formica F, Avalli L, Colagrande L, Ferro O, Greco G, Maggioni E, et al. Extracorporeal membrane oxygenation to support adult patients with cardiac failure: predictive factors of 30day mortality. Interact Cardiovasc Thorac Surg 2010;10:721-6. 
${ }^{9}$ Elsharkawy HA, Li L, Esa WA, Sessler DI, Bashour CA. Outcome in patients who require venoarterial extracorporeal membrane oxygenation support after cardiac surgery. J Cardiothorac Vasc Anesth 2010;24:951-6.

${ }^{10}$ Loforte A, Montalto A, Ranocchi F, Della Monica PL, Casali G, Lappa A, et al. Peripheral extracorporeal membrane oxygenation system as salvage treatment of patients with refractory cardiogenic shock: preliminary outcome evaluation. Artif Organs 2012;36:E53-E61.

${ }^{11}$ Chrysostomou C, Morell VO, Kuch BA, O’Malley E, Munoz R, Wearden PD. Short-and intermediate-term survival after extracorporeal membrane oxygenation in children with cardiac disease. J Thorac Cardiovasc Surg 2013;146:317-25.

${ }^{12}$ Bakhtiary F, Keller H, Dogan S, Dzemali O, Oezaslan F, Meininger D, et al. Venoarterial extracorporeal membrane oxygenation for treatment of cardiogenic shock: clinical experiences in 45 adult patients. J Thorac Cardiovasc Surg 2008;135:382-8.

${ }^{13}$ Le Gall JR, Lemeshow S, Saulnier F. A new simplified acute physiology score (SAPS II) based on a European/North American multicenter study. JAMA 1993;270:2957-63.

${ }^{14}$ Ferreira FL, Bota DP, Bross A, Mélot C, Vincent JL. Serial evaluation of the SOFA score to predict outcome in critically ill patients. JAMA 2001;286:1754-8.

${ }^{15}$ Knaus WA, Draper EA, Wagner DP, Zimmerman JE. APACHE II: a severity of disease classification system. Crit care med 1985;13:818-29.

${ }^{16}$ Wu VC, Tsai HB, Yeh YC, Huang TM, Lin YF, Chou NK, et al. Patients supported by extracorporeal membrane oxygenation and acute dialysis: acute physiology and chronic health evaluation score in predicting hospital mortality. Artif Organs 2010;34:828-35.

${ }^{17}$ Tsai CW, Lin YF, Wu VC, Chu TS, Chen TM, Hu FC, et al. SAPS 3 at dialysis commencement is predictive of hospital mortality in patients supported by extracorporeal membrane oxygenation and acute dialysis. Euro J Cardiothorac Surg 2008;34:1158-64. 
${ }^{18}$ Lin CY, Tsai FC, Tian YC, Jenq CC, Chen YC, Fang JT, et al. Evaluation of outcome scoring systems for patients on extracorporeal membrane oxygenation. Ann Thorac Surg 2007;84:1256-62.

${ }^{19}$ Lamb K, Hirose H, Cavarocchi NC. Preparation and Technical Considerations for Percutaneous Cannulation for Veno-Arterial Extracorporeal Membrane Oxygenation. J Cardiac Surg 2013; 28:190-2.

20 Pappalardo F, Pieri M, Greco T, Patroniti N, Pesenti A, Arcadipane A, et al. Predicting mortality risk in patients undergoing Venovenous ECMO for ARDS due to influenza A (H1N1) pneumonia: the ECMOnet score. Intensive Care Med 2013;39:275-81.

${ }^{21}$ Schmidt M, Zogheib E, Rozé H, Repesse X, Lebreton G, Luyt CE, Trouillet JL, Bre' chot N, Nieszkowska A, Dupont H, Ouattara A, Leprince P, Chastre J, Combes A. The PRESERVE mortality risk score and analysis of long-term outcomes after extracorporeal membrane oxygenation for severe acute respiratory distress syndrome. Intensive Care Med 2013;39:17041713.

22 United Network for Organ Sharing (UNOS). Questions and Answers for Transplant Candidates about MELD and PELD. Talking About Transplantation 2008. http://www.unos.org/docs/MELD_PELD.pdf [Accessibility verified December 6, 2014]. ${ }^{23}$ Hoste EA, Clermont G, Kersten A, Venkataraman R, Angus DC, De Bacquer D, et al. RIFLE criteria for acute kidney injury are associated with hospital mortality in critically ill patients: a cohort analysis. Crit Care. 2006;10:R73. Epub 2006 May 12. 